\title{
María Jesús Zamora Calvo (ed.), Mujeres quebradas. La Inquisición y su violencia hacia la heterodoxia en Nueva España, España, Iberoamericana/Vervuert, 2018, 330 págs.
}

Resaltando el carácter masculino de la Inquisición y su lóbrega actividad, María Jesús Zamora Calvo nos entrega una compilación necesaria. Desde una mirada multidisciplinaria con enfoque divulgativo, esta compilación centra su atención en las mujeres y su inserción punitiva en el funcionamiento inquisitorial a partir de los registros producidos para dar cuenta de su comportamiento frente al Santo Oficio novohispano entre los siglos XVI y XVIII. Al igual que otros espacios históricamente misóginos, los artículos reunidos estudian las violencias vividas por mujeres en contacto con esta institución protectora de la ortodoxia católica. Y a su vez, encontramos rasgos de la fuerza femenina que se sobrepuso al panorama adverso, excediendo la impronta inquisitorial sobre su existencia.

Alberto Ortiz comienza la serie con una mirada teórica sobre la conformación del chivo expiatorio femenino desde el cual tomó fuerza la actividad inquisitorial. El autor destaca la longevidad argumentativa que constituye una maldad femenina, divulgada e interiorizada en el imaginario social del occidente judeocristiano, desbordante al Santo Oficio. El miedo y la ignorancia incrustaron sobre las mujeres variables de vulnerabilidad, credulidad, poder erótico, brujería y disonancia natural con el objetivo de bosquejar institucionalmente una víctima y justificar la persecución. Así, los encargados del examen ortodoxo, los beneficiados de la actividad mágica, y hasta las propias acusadas, sustentaban estereotipos sociales sobre mujeres dedicadas a subsistir ejecutando conocimientos populares. Elaborados los requerimientos atribuidos a la actividad hechicera y demoniaca, se daba inicio a la persecución y se justificaba rigurosamente la condena.

Desde el análisis documental, Yadira Munguía indaga los versos poéticos femeninos coaptados y oscurecidos por el Santo Oficio. Tras una descripción de las variables que limitaban la producción escritural a un sector privilegiado de mujeres seglares y religiosas, la autora amplifica otras voces femeninas además de la ya reconocida Juana Inés de la Cruz. Si bien hay un incremento de la participación literaria femenina, cuya cumbre se encuentra en el siglo XVIII, el Santo Oficio fue más laxo al vincular mujeres, texto y pecado, principalmente por los prejuicios que circundaban sobre su capacidad intelectual. La autora menciona que son pocos los procesos inquisitoriales contra mujeres que incluyeron versos como errores de fe, a pesar de 
contener rasgos que cumplían con el perfil herético buscado por la Inquisición. Ciertamente, como menciona Munguía, la investigación documental podría modificar este primigenio panorama, amplificando poetisas que no lograron masificar su producción literaria.

Criticando la capacidad de entendimiento total de los fenómenos culturales desde la esfera jurídica, Manuel Pérez y Paola Monreal nos advierten de características desbordantes a los marcos jurídicos inquisitoriales, y que residen más bien en realidades literarias. Desde acusaciones y autodenuncias de hechicería popular en San Luis de Potosí (1629), los autores despliegan su prisma sobre descripciones de actividades populares de hechicería erótica benigna, que involucró mayormente a mujeres. Analizando distintos casos, el artículo resalta la presencia de motivos literarios orales tradicionales de larga data, expresiones en último término de la cotidianeidad social. Por otro lado, la hechicería no sería sólo femenina, sino que participarían los hombres desde la activación del poder simbólico mágico, buscando subvertir -en este caso- su realidad sexual y erótica.

Recobrando los edictos de fe sobre beatas, curanderas, parteras, hechiceras y brujas, Graciela Rodríguez analiza la normativa inquisitorial que se desplegó sobre el entramado mágico-religioso cotidiano del Zacatecas colonial. Operativamente, el control social que ejerció el Santo Oficio fue dirigido a grupos no indígenas, ex- cluidos y vulnerables. Especialmente involucró a mujeres de estratos sociales marginales, quienes se volcaban en prácticas mágicas y religiosas a fin de sobrevivir y encontrar salidas al adverso panorama social y dominación masculina. Las categorizaciones penales del Santo Oficio representan actividades funcionales en la sociedad zacatecana, siendo ocupaciones de consulta cotidiana, aisladas y perseguidas por las estructuras normativas. Así, concluye Rodríguez, el poder también correspondía a mujeres excepcionales consideradas institucionalmente como transgresoras, que ocuparon sus conocimientos para abrirse paso en una sociedad fuertemente estratificada.

En el quinto ensayo Esther Cohen presenta cómo los grupos criptojudaicos novohispanos buscaron mantener una práctica simbólica esencial en la tradición judía, la circuncisión, en un tiempo de persecuciones sistemáticas. La respuesta masculina fue la inclusión femenina en una actividad exclusiva de ellos. Las prácticas cotidianas hebreas eran esenciales dentro de su confesionalización, y por ende su pervivencia aseguraba la reproducción de su tradición religiosa. $\mathrm{El}$ caso analizado de circuncisión femenina -la extracción de un trozo de carne desde los hombros del cuerpo femenino, luego consumido por familiares- describe cómo Isabel de Núñez y sus hijas Antonia y Clara, fueron involucradas en violentos métodos con el fin del resguardo simbólico en tiempos del ocaso criptojudío novohispano hacia 1640-1650. Cohen 
advierte de las fuertes contradicciones sagradas que esta adaptación conllevó. El caso demuestra las consecuencias de la presión inquisitoria, así como la mutilación que afectó al rito tradicional hebreo sin mediar consecuencias para sus participantes.

Desde el juicio contra María de Rivera, María Jesús Torquemada desmadeja las etapas judiciales por las cuales transitaba una mulata acusada por el Santo Oficio, y cómo se definían los objetivos purgables sobre ella. Considerando la actividad inquisitorial en España y México, la autora encuadra el rigor reiterativo y uniforme de esta institución con elementos materiales y literarios tradicionalmente sospechosos de herejía. A medida que avanzaba el flujo burocrático, las denuncias de colegas, testigos-clientes, las declaraciones forzadas de la propia acusada y sus condiciones sociales eran conducidos a confirmar temores heterodoxos habituales. Finalmente, castigos con características preventivas aislaban a la imputada, coronando el proceso inquisitivo burocrático de cotejo herético.

José Enciso Contreras y José Espinoza Zúñiga analizan el proceder inquisitorial contra un grupo de vecinos en Nombre de Dios hacia 1666, destacando el factor político que marcó las decisiones inquisitoriales contra la heterodoxia. Las denuncias involucraron a participantes de tertulias organizadas por el vicario de la villa, específicamente a sus protegidas. Felipa Canchola, una mestiza que se jactaba, entre otras cosas, de realizar transmutaciones animalescas, y María de Valenzuela, sindicada como bruja maestra. Iniciadas las pesquisas, la actividad inquisitorial del comisario estuvo fuertemente mediada por disputas entre el clero secular y el Santo Oficio, lo que dilató y obstaculizó el proceso de denuncias, descartando incluso la citación de las imputadas. De este modo la elaboración del caso se acercó a una verdad judicial, construcción de hechos desde la sapiencia del funcionario y declaraciones de oídas, mostrando rasgos ligados a la tradición europea y su prototipo de aquelarres. La sentencia tampoco fue rigurosa. Los autores comentan finalmente el papel de las negociaciones entre comisarios y acusados, que en este caso involucraban a miembros de una importante familia con autoridad eclesiástica.

En una mirada global, Robin Ann Rice destaca la cotidianeidad y aceptación de diversas manifestaciones supersticiosas benignas realizadas por mujeres. Una sociedad novohispana con múltiples influencias culturales, una religiosidad cristiana más popular que intelectual, y con la influencia devocional medieval de los frailes, propició la creencia de estas expresiones, gozando frecuentemente de la venia inquisitorial. La intervención procesal del Santo Oficio sobre prácticas de magia blanca estuvo ligada principalmente a decisiones políticas, para mantener la autoridad vigente y salvaguardar a sospechosos vinculados con altos cargos. El perfil inquisitorial corruptible y poco activo marcó su inercia sobre lo devocional, siendo más bien una ins- 
tancia de liberación catártica y control social. La autora incluye casos en los cuales se involucraban sentidos cristianos de devoción con magia y ritos supersticiosos, definiéndose un espacio novohispano alejado de la modernidad y de la presión ortodoxa inquisitorial.

Mariana Masera recorre el cielo, purgatorio e infierno desde oraciones, conjuros y ensalmos utilizados por mujeres, principalmente con fines mágicos y eróticos. Siendo especialistas o beneficiarias, las usuarias de estas prácticas conformaron y transmitieron saberes orales provenientes de espacios periféricos, cristalizando un lenguaje que incluía elementos de la cultura colonial oficial. La autora destaca la presencia discursiva de personajes cristianos tradicionales, habitantes de los niveles celestiales mencionados, como mediadores divinos en demandas terrenales. Palabras específicas, ritmos y actos componían un discurso normado, con requerimientos necesarios para asegurar una efectiva intervención. Amuletos y elementos provenientes de la riqueza cultural novohispana acompañaban estos susurros imparables, escurridizos al control inquisidor, animadores de un perdurable imaginario cultural.

En 1706, Simona de los Santos denuncia a Antonia de Santiago y Sebastiana Santiago de brujería, siendo testigo de un pájaro negro que entraba en la boca de Antonia mientras dormía. Así conseguía objetos de valor en un espacio marginal. Analizando la acusación, José Manuel
Pedrosa presenta su contenido como expresión de conocidos cuentos tradicionales elaborados desde el medioevo. Animales que emergen de la boca, sueños premonitorios, almas que deambulan fuera del cuerpo y su retorno épico, tesoros escondidos, y solidaridades entre protagonistas, son algunas de las representaciones compartidas y distantes en tiempo y espacio. La recepción de denuncias con estos elementos demuestra a su vez cómo desaguan en la historia distintas expresiones folclóricas, y cómo se adecúan a una lista de cotejo penal. Para el autor, la denuncia guatemalteca insta a observar la realidad desde un prisma maravilloso, ajustes históricos de tradiciones heredadas. A su vez, la absoluta presencia masculina protagonista de los cuentos analizados fue el canal utilizado por la denunciante contra sus pares, expresión del trasvasije femenino de la cultura dominante.

Cecilia López Ridaura estudia un expediente inquisitorial de 1760 que contiene adosado un muñeco utilizado con fines maléficos por María Guadalupe. Contra los problemas que la aquejaban, esta mulata buscó variadas soluciones mágicas, elaboró fetiches y conformó alianzas con otras mujeres hechiceras, y practicó vuelos y pactos demoniacos. En sus declaraciones, transversalmente se encuentra el miedo a ser descubierta por su marido y el constante arrepentimiento de sus actos en nombre de Dios, factores que no coartaron su actividad. Empero, las múltiples descripciones y denuncias que la acoplaron a sus pares europeas no facilitó el 
caso. El proceso fue dilatado por varios años, $y$ en instancias finales los calificadores cuestionaron varias pruebas, sin poder ser comprobada, por ejemplo, la negación de la mujer hacia Dios. La complejidad supersticiosa y la actividad de los funcionarios a cargo fue determinante, obstaculizando una resolución institucional ortodoxa expedita y esperada.

En el interior de las epístolas de María Coleta, religiosa capuchina de mediados del siglo XVIII, Anel Hernández Sotelo analiza los padecimientos externos e internos que sufría la religiosa, acusada de alumbrada y herética junto su confesor. Proveniente de un contexto histórico de orfandad religiosa capuchina y dolencias físicas importantes, la acusada se vio envuelta en las voluntades de distintos confesores que la acompañaron en sus experiencias monacales paranormales, sin encontrar alivios. Desde el prisma border thinking, su otredad quedó cubierta por la universalidad abstracta que contorneaba su actividad. Los escritos forzados de la capuchina eran utilizados por hombres religiosos que se autodenominaban canalizadores de sus experiencias, divulgando sus milagros y desestimando explicaciones médicas propensas a anular una intervención divina. Del mismo modo, sus actividades fueron válvula de escape para la élite oaxaqueña que vivía tiempos de revueltas y cuestionamientos de su autoridad. La autora propone mirar detenidamente en la otredad de estas experiencias y los alcances subjetivos que emergen en este tipo de escritura que representa la potencia de Dios.

La Inquisición ha sido y sigue siendo preocupación de diversos estudios. Esta compilación abre nuevas perspectivas sobre el fenómeno mágico-heterodoxo, las contradicciones inquisitoriales novohispanas y la actividad femenina que rebasó canales institucionales de norma y control. Comenzando en las violencias inquisitoriales y sus registros documentales, las y los autores presentan las experiencias de diversas mujeres que buscaron escapar de las presiones y enfrentar la dominación masculina, movilizando prácticas desde ambos lados de la frontera colonial cristiana e indígena local. Las miradas multidisciplinarias que conforman este libro alientan la curiosidad sobre las formas históricas de opresión hacia las mujeres, temática necesaria que trae nuevos bríos analíticos a problemas tradicionales y longevos.
Erick E. Figueroa Ortiz Universidad de Chile 